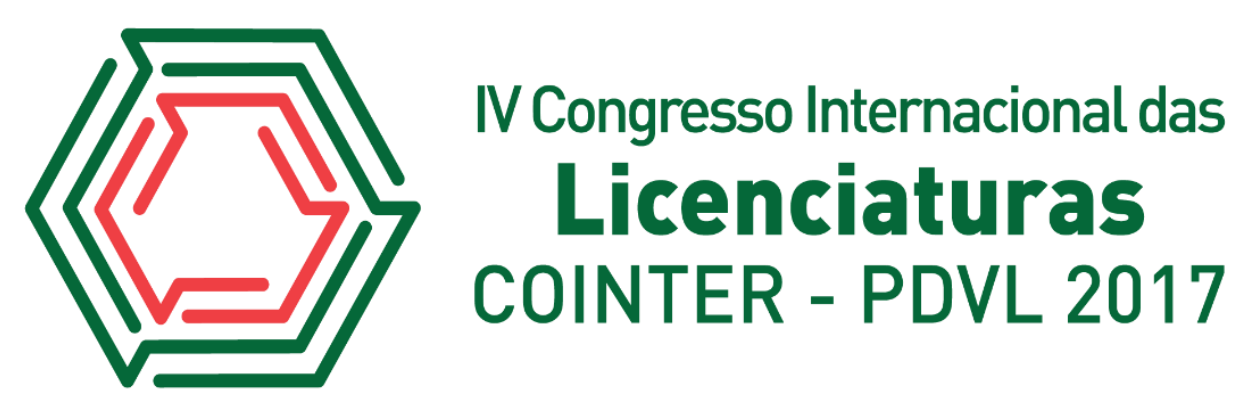

\title{
A DICOTOMIA ENTRE TEORIA E PRÁTICA NAS AULAS DE FÍSICA: TRABALHANDO A CINEMÁTICA NOS LANÇAMENTOS DE FOGUETES DIDÁTICOS.
}

\author{
Apresentação: Pôster
}

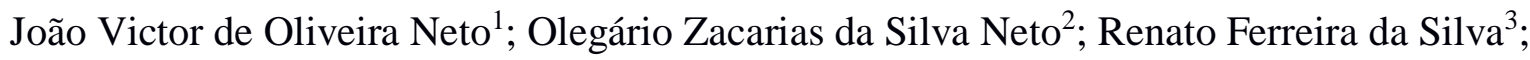
Joseilda Viana de Oliveira ${ }^{4}$; Maria Emília Barreto Bezerra ${ }^{5}$
\end{abstract}

\section{Introdução}

Sabe-se que a Física, sem dúvidas, é uma das áreas de estudo mais importantes para o desenvolvimento humano, tendo diversas aplicações como, por exemplo, na Medicina, nas Engenharias, nas áreas Tecnológicas, etc. Todavia, é bastante comum que nas aulas de Física os alunos do Ensino Médio encontrem dificuldades para entender os diversos conceitos que fazem parte desta disciplina, além das dificuldades em compreender de forma satisfatória sua linguagem matemática. Geralmente, essas dificuldades acabam afetando o fascínio, isto é, o interesse em se estudar essa disciplina tão importante e presente em nosso cotidiano.

Para alguns pesquisadores do Ensino de Física os problemas encontrados pelos discentes em compreender a disciplina se dá pela forma com que, eventualmente, essa ciência é trabalhada em sala de aula (NARDI, 2004). Muitas vezes os professores recorrem às atividades experimentais para que haja maior participação dos alunos nas aulas. Normalmente o docente ministra a aula explicando todos os conceitos e cálculos envolvidos no conteúdo e, em seguida, apresenta aos alunos um experimento que os remete ao que foi estudado. A indagação que se pode fazer é: porque mesmo com o uso da atividade experimental, ainda existe tanta dificuldade na parte teórica do conteúdo?

Embora as atividades experimentais sejam de extrema importância no processo de ensino-

\footnotetext{
${ }^{1}$ Licenciatura em Física, IFRN, zmayster_@hotmail.com.

${ }^{2}$ Licenciatura em Física, IFRN, olegario.neto@outlook.com.

${ }^{3}$ Licenciatura em Física, IFRN, renato_ferreira1777@hotmail.com.

${ }^{4}$ Supervisora do PIBID Subprojeto Interdisciplinar do IFRN Campus Santa Cruz, Escola Estadual Maria Lídia da Silva, joseildaviana@hotmail.com.

${ }^{5}$ Mestra em Ensino de Ciência Naturais e Matemática, Coordenadora de área do PIBID Subprojeto Interdisciplinar do IFRN Campus Santa Cruz, emilia.bezerra@ifrn.edu.br.
} 
aprendizagem das ciências, elas não devem ser utilizadas apenas para a "ilustração" dos conceitos. O professor deve planejar suas aulas pensando sempre em relacionar as atividades práticas aos conceitos teóricos trabalhados em sala de aula, caso contrário, além de não colaborar para a compreensão da teoria, a atividade experimental pode ser vista pelos próprios alunos como algo para "passar o tempo de aula".

Diante da problemática apresentada nas aulas de Física, os bolsistas do Programa Institucional de Bolsas de Iniciação à Docência (PIBID) Subprojeto Interdisciplinar do IFRN Campus Santa Cruz desenvolveu uma atividade na Escola Estadual Professora Maria Lídia da Silva, localizada em São Bento do Trairi/RN, que consiste em lançamentos de foguetes didáticos, para trabalhar os conteúdos da Cinemática com o propósito de relacionar teoria e prática.

\section{Fundamentação Teórica}

A dificuldade de o aluno relacionar teoria e prática no Ensino de Ciências é objeto de bastante discussão. Segundo Freire (1997), para compreender a teoria é preciso experienciá-la. Os experimentos são mecanismos essenciais para o aprendizado de ciências. Gaspar (2009) também destaca a importância da atividade experimental, e afirma ainda que a mesma tem vantagens sobre a teórica, porém, ambas devem caminhar juntas, pois uma completa a outra. Ambos corroboram com Lima, Aguiar Júnior e Braga, quando afirmam que "A ciência é uma construção dialética onde a teoria e prática são interdependentes" (1999, P.21).

É evidente que o uso de experimentos para o aprendizado de ciências é indispensável para o aprendizado do aluno, contudo, as escolas públicas não oferecem, em geral, estruturas, como laboratórios, para a realização de tais atividades. Em vista disso, os professores devem procurar meios alternativos de relacionar teoria e prática, fazendo com que as aulas sejam mais atrativas. Cruz (2008) comenta que não há necessidade de laboratórios e materiais sofisticados para a realização das atividades experimentais, é possível utilizar materiais alternativos na ausência do ideal. Foi exatamente esse pensamento que ajudou os bolsistas PIBID na realização dessa atividade.

\section{Metodologia}

A presente atividade foi idealizada pelos bolsistas PIBID do Subprojeto Interdisciplinar para ser realizada com os alunos do $2^{\circ}$ ano do Ensino Médio da Escola Estadual Professora Maria Lídia 
da Silva. A metodologia empregada, trata-se da construção de foguetes didáticos para trabalhar os conceitos de Cinemática de forma lúdica e prática.

O exercício proposto aos alunos se deu em duas etapas: a primeira voltada para a construção dos foguetes, pelos próprios alunos, e a segunda, voltada para o lançamento dos foguetes, juntamente com a atividade teórica.

É importante ressaltar que para a construção do foguete didático foram utilizados apenas materiais de baixo custo e de fácil acesso, sendo eles:

- 02 Garrafas Pet de dois litros;

- Fita Adesiva;

- Tesoura;

- Papelão

- Tinta Spray ou Guache.

A base de lançamento dos foguetes, constituída de canos e materiais metálicos que permitem escolher o ângulo de lançamento, e a bomba de ar (a mesma utilizada para encher pneus de bicicletas), que tem papel de impulsionar o foguete, foram disponibilizadas pelos bolsistas aos alunos que, por sua vez, foram orientados então na montagem dos foguetes na primeira etapa da atividade.

O trabalho foi realizado em quatro grupos, sendo assim, foram confeccionados quatro foguetes. A construção se resume em fazer cortes nas garrafas pets e as juntar para que fiquem no formato padrão de um foguete, deixando uma das garrafas fechada. Essa garrafa fechada é o reservatório do foguete, que na atividade, tem a água como seu combustível. O papelão é utilizado para fazer as aletas do foguete enquanto que as tintas são utilizadas na decoração dos experimentos, que fica a critério dos discentes.

$\mathrm{Na}$ segunda etapa os alunos foram direcionados, com autorização dos professores e diretor da escola, para um campo de futebol próximo à escola, que por se tratar de um espaço amplo, foi utilizado para se realizar os lançamentos dos foguetes. Com o auxílio de uma trena, mediu-se o comprimento total do campo em uma mesma direção, para se ter noção da distância percorrida pelo foguete. Como a ideia da atividade é relacionar teoria e prática, nesta etapa, os quatro grupos de alunos tinham como objetivo principal além de lançar seus foguetes didáticos, responder a duas 
perguntas elaboradas pelos bolsistas. Sendo estas:

01. Como é possível calcular a velocidade média escalar atingida pelo foguete?

02. Essa velocidade é a velocidade real obtida pelo foguete?

Essas perguntas foram pressupostos para uma discussão mais ampla da cinemática e seus cálculos. As respostas para as indagações foram obtidas ao decorrer da atividade pelos grupos de alunos, com os bolsistas, a todo o momento, intervindas na atividade com comentários construtivos para a melhor compreensão dos conceitos físicos.

\section{Resultados e Discussões}

A partir da atividade realizada pelos discentes com ajuda dos bolsistas PIBID e suas respostas, podem ser apontados alguns resultados importantes neste trabalho.

Inicialmente, é notório o envolvimento dos alunos na atividade. Embora não se trate de uma atividade avaliativa, onde se podem obter notas, os alunos tiveram uma participação bastante significativa.

No que diz respeito as perguntas, apresentadas anteriormente, os discentes chegaram a conclusão de que, como o comprimento do campo era conhecido, para calcular a velocidade média escalar bastava escolher um referencial como sendo $\mathrm{X}_{0}$, e após o lançamento, contabilizar o tempo gasto até que o foguete atingisse o solo numa uma posição $X$, e então utilizar a expressão: $V m e ́ d=\frac{X-X_{0}}{\Delta t}($ para a velocidade na horizontal $)$.

A segunda pergunta evidenciou uma carência dos discentes nos demais conteúdos da cinemática. Os mesmos não conseguiram descrever se o resultado obtido por eles era realmente a velocidade real descrita pelo projétil.

Então, aproveitou-se desse momento da aula prática, para que o grupo de bolsistas discutisse alguns conceitos de lançamentos horizontal, vertical e oblíquo e, ainda, queda livre. Chegando à conclusão de que aquele valor só era válido para a velocidade horizontal do foguete quando é considerada constante. Fato que, na prática, não ocorre, já que se trata de um lançamento oblíquo, assim o foguete tem velocidade tanto na horizontal , quanto na vertical, sofrendo ação da gravidade, tendo velocidade variável ao longo da trajetória, além de outros fatores que contribuem para os resultados reais, como a resistência do ar. 
Imagem 01: Alunos realizando lançamento de foguetes didáticos. Fonte: Própria.

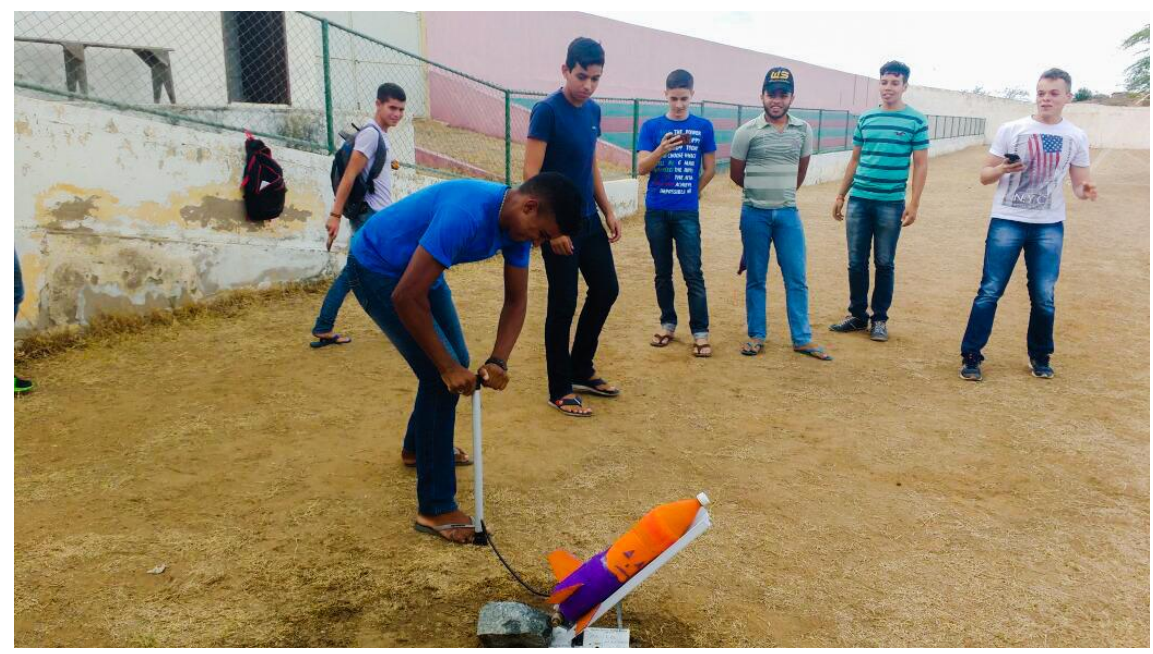

\section{Conclusões}

Perante os resultados obtidos no presente trabalho, conclui-se que a atividade prática experimental é fundamental no processo de ensino aprendizagem da Física, pois, a mesma, se trabalhada de forma planejada, buscando sempre conciliar teoria e prática, é uma forte ferramenta motivacional para o estudo dos diversos conteúdos desta disciplina.

É importante mencionar ainda que a atividade também contribuiu de forma significativa para a formação dos bolsistas PIBID, licenciandos em Física do IFRN Campus Santa Cruz, pois permitiu uma aproximação com o trabalho docente, utilizando uma metodologia não trivial.

\section{Referências}

CRUZ, Dalva Aparecida. Atividades prático-experimentais: tendências e perspectivas. Londrina, 2008.

Disponível

em:

http://www.gestaoescolar.diaadia.pr.gov.br/arquivos/File/producoes_pde/artigo_dalva_aparecida_cr uz.pdf . Acesso em: 15 out. 2017.

FREIRE, P. Pedagogia da autonomia: saberes necessários à prática educativa. Rio de Janeiro: Paz e Terra, 2005.

GASPAR, A. Experiências de Ciências para o Ensino Fundamental. São Paulo: Ática, 2009.

LIMA, M. E. C.; AGUIAR JUNIOR, O. G. de; BRAGA, S. A. de M. Aprender Ciências: um mundo de materiais. Belo Horizonte: UFMG, 2004.

NARDI, Roberto. Pesquisas em Ensino de Física. 3 ed. São Paulo: Escrituras, 2004. 